\title{
A UTILIZAÇÃO DAS FONTES DO SILEXITO PELOS GRUPOS PRÉ- HISTÓRICOS E SUA REDISTRIBUIÇÃO ESPACIAL NA MESORREGIÃO CENTRAL DO RIO GRANDE DO NORTE, BRASIL
}

\author{
Valdeci dos Santos Júnior'
}

\begin{abstract}
Resumo: Este artigo levanta uma hipótese de cunho geológico sobre a origem das fontes de silexito distribuídas na bacia hidrográfica do rio Piranhas-Açu, na mesorregião central do Estado do Rio Grande do Norte. Essas fontes de silexitos aparecem de forma expressiva em boa parte daquela região, localizadas em paleocascalheiras existentes em áreas de tabuleiros, leitos e margens de riachos, sendo utilizadas intensamente por grupos pré-históricos para efetuar lascamentos visando elaborar artefatos líticos. Um sistema composto por duas falhas tectônicas (Afonso Bezerra e Carnaubais) teria sido a origem dos fatores naturais que levaram aos processos de silicificação das rochas carbonáticas e sua redistribuição na mesorregião central potiguar. PalavrasChave: Silexito; Fontes de matérias-primas; Pré-história Potiguar.
\end{abstract}

\begin{abstract}
This article raises a geological hypothesis about the origin of the silexite sources distributed in the Piranhas-Açu river, basin in the central meso-region of the Rio Grande do Norte State. These sources of silexites appear expressively in a large part of that region, located in paleogravels existing in areas of trays, beds and banks of streams, being used intensely by prehistorical groups to effect chipping in order to elaborate lithic artifacts. A system composed of two tectonic faults (Afonso Bezerra and Carnaubais) would have been the origin of the natural factors that led to the processes of silicification of the carbonate rocks and their redistribution in the Potiguar central mesoregion. Keywords: Silexite. Sources of raw materials. Potiguar prehistory.
\end{abstract}

i Departamento de História da Universidade Estadual do Rio Grande do Norte - UERN 
A Utilização das Fontes do Silexito pelos Grupos Pré-Históricos e sua Redistribuição Espacial na Mesorregião Central do Rio Grande do Norte, Brasil.

\section{Introdução}

No cotidiano da Arqueologia é comum o uso do termo sílex e, por vezes, silexito para identificar esses nódulos rochosos silicificados, então se torna necessário adotar preliminarmente um posicionamento terminológico que identificasse, explicitamente, o termo adequado a ser utilizado na análise do material lítico tendo essas rochas silicosas ${ }^{1}$ como matérias primas.

Tendo em vista a diversidade de nódulos rochosos com diferentes graus de silicificação e tonalidades, localizados em diferentes lugares na mesorregião central do Rio Grande do Norte e que foram utilizados como matérias-primas nos lascamentos para elaboração de instrumentos pelos grupos pretéritos foi necessário, inicialmente, agrupar essas matériasprimas rochosas no sentido terminológico. Essas diferenças litológicas, por vezes, podem ser caracterizadas facilmente em nível macroscópico pela simples observação visual e do tato, mas por vezes torna-se necessário chegar à análise em nível microscópico para se chegar a identificação final de uma rocha silicosa.

O conceito de sílex, no sentido etimológico, evidencia uma "pedra dura" ou qualquer objeto duro (Araújo, 1991) sendo uma rocha sedimentar de precipitação química monominerática, de origem diagenética, a partir de uma lama ou vasa predominantemente carbonatada biogênica ainda não consolidada, tendo em sua composição quartzo microcristalino (tipo calcedônia) e quantidade de megaquartzo, além de quantidade menores de impurezas diversas.

Para além da componente diagenética, a substituição metassomática está presente, por exemplo, na silicificação de foraminíferos e de macro fósseis (conchas e carapaças) inicialmente carbonatados. Pode se apresentar sob a forma de camadas ou nódulos (concreções) através da substituição molecular de carbonatos de cálcio pela sílica², sob a forma de quartzo, opala ou calcedônia nas rochas calcárias pelo processo da silicificação (Suguio, 2003).

1 Os principais minerais das rochas silicosas de gênese química são o quartzo, a calcedônia e a opala. Esses minerais são compostos essencialmente por sílica, e os diferentes nomes se referem a diferentes padrões de arranjos cristalinos (ou ausência dos mesmos, no caso da opala). (Araújo, 1991, p.106).

2 A sílica em sílex pode ter origem biológica ou química. No primeiro caso, a remobilização de sílica biogênica gera depósitos silicosos secundários, o que pode ser inferido pela presença de fósseis silicosos na pilha sedimentar (Calça, 2008, p.63). 
No sentido arqueológico, Araújo (1991) critica a utilização do termo sílex para denominar qualquer rocha silicosa apta ao lascamento, o que tem levado a imprecisões relevantes ao tentar particularizar elementos como a calcedônia, por exemplo, que é tão somente um mineral constituinte de uma rocha, e nunca uma rocha, preferindo utilizar o termo silexito (que seria o sinônimo da palavra inglesa chert) que agruparia todas as rochas silicosas de gênese química, dos quais o sílex seria apenas uma delas (Araújo, 1991). Ele propôs uma classificação em termos de nomenclatura, o uso do termo silexito em sete grupos com a seguinte estruturação (Quadro 1):

Quadro 1 - Proposta de nomenclatura do termo silexito para designar as rochas silicosas quimicamente formadas.

\begin{tabular}{|c|c|c|}
\hline \multicolumn{3}{|c|}{ SILEXITO } \\
\hline GRUPO & CARACTERÍSTICA & SUBGRUPOS \\
\hline \multirow{4}{*}{ Maciços } & \multirow{4}{*}{$\begin{array}{l}\text { Silexitos maciços, não apresentando bandamento, } \\
\text { acamamento ou qualquer feição de descontinuidade. }\end{array}$} & Sílex \\
\hline & & Jaspe \\
\hline & & Novaculita \\
\hline & & Porcelanito \\
\hline \multirow{2}{*}{ Bandados } & \multirow{2}{*}{$\begin{array}{l}\text { Apesentam estratificação de bandamentos e caracterizam-se } \\
\text { por apresentar descontinuidades. }\end{array}$} & Ágata \\
\hline & & Estratificado \\
\hline Nodulares & \multicolumn{2}{|c|}{$\begin{array}{l}\text { Apresentam feições estruturais com reflexos de uma concentração de impurezas } \\
\text { ou de diferenças mineralógicas e texturais. }\end{array}$} \\
\hline Brechóides & \multicolumn{2}{|c|}{$\begin{array}{l}\text { Apresentam estrutura assemelhada ao grupo dos silexitos nodulares, diferindo } \\
\text { quanto ao aspecto, mostrando contornos abruptos e bem delineados. }\end{array}$} \\
\hline Oolíticos & \multicolumn{2}{|c|}{$\begin{array}{l}\text { São frutos da substituição química de sedimentos carbonáticos por sílica, onde o } \\
\text { sedimento original era um calcário oolítico. A sílica ao substituir o carbonato, } \\
\text { tende a preservar as formas dos oólitos. }\end{array}$} \\
\hline Fossilíferos & \multicolumn{2}{|c|}{$\begin{array}{l}\text { Apresentam fósseis em seu interior (geralmente conchas e carapaças de animais } \\
\text { marinhos) que vieram de um sedimento carbonático, que sofreu substituição } \\
\text { química por sílica. }\end{array}$} \\
\hline Estromatolíticos & \multicolumn{2}{|c|}{$\begin{array}{l}\text { São estruturas compostas de sedimentos carbonáticos que possuíam algas } \\
\text { filamentosas e posteriormente cimentados tendo, em seguida, o carbonato sendo } \\
\text { substituído pela sílica. }\end{array}$} \\
\hline
\end{tabular}

Fonte: (Araújo, 1991, pp.108 a 110 - Adaptado pelo autor).

Nesse sentido o conceito de silexito, apesar de bastante assemelhado ao do sílex, é mais abrangente ao se caracterizar como uma rocha sedimentar não-clástica, com granulação de finíssima a fina, fratura conchoidal, dura, composta por opala, calcedônia e quartzo criptocristalino ou de uma mistura deles, que abrange todas as rochas silicosas (Meneses, 2008). Tendo em vista que na mesorregião central Potiguar aparecem fragmentos litológicos com tonalidades e graus variados de silicificação (Figura 1) em nível macroscópico, que podem 
A Utilização das Fontes do Silexito pelos Grupos Pré-Históricos e sua Redistribuição Espacial na Mesorregião Central do Rio Grande do Norte, Brasil.

ser enquadrados em praticamente todos os grupos de silexito, tais como, maciços, bandados, nodulares, brechóides e fossilíferos, torna-se necessário usar a nomenclatura geral de silexito para designar todos os fragmentos rochosos que sofreram processos químicos de silicificação ${ }^{3}$ e que foram utilizados como matérias-primas pelos grupos pré-históricos para atividades de lascamentos.
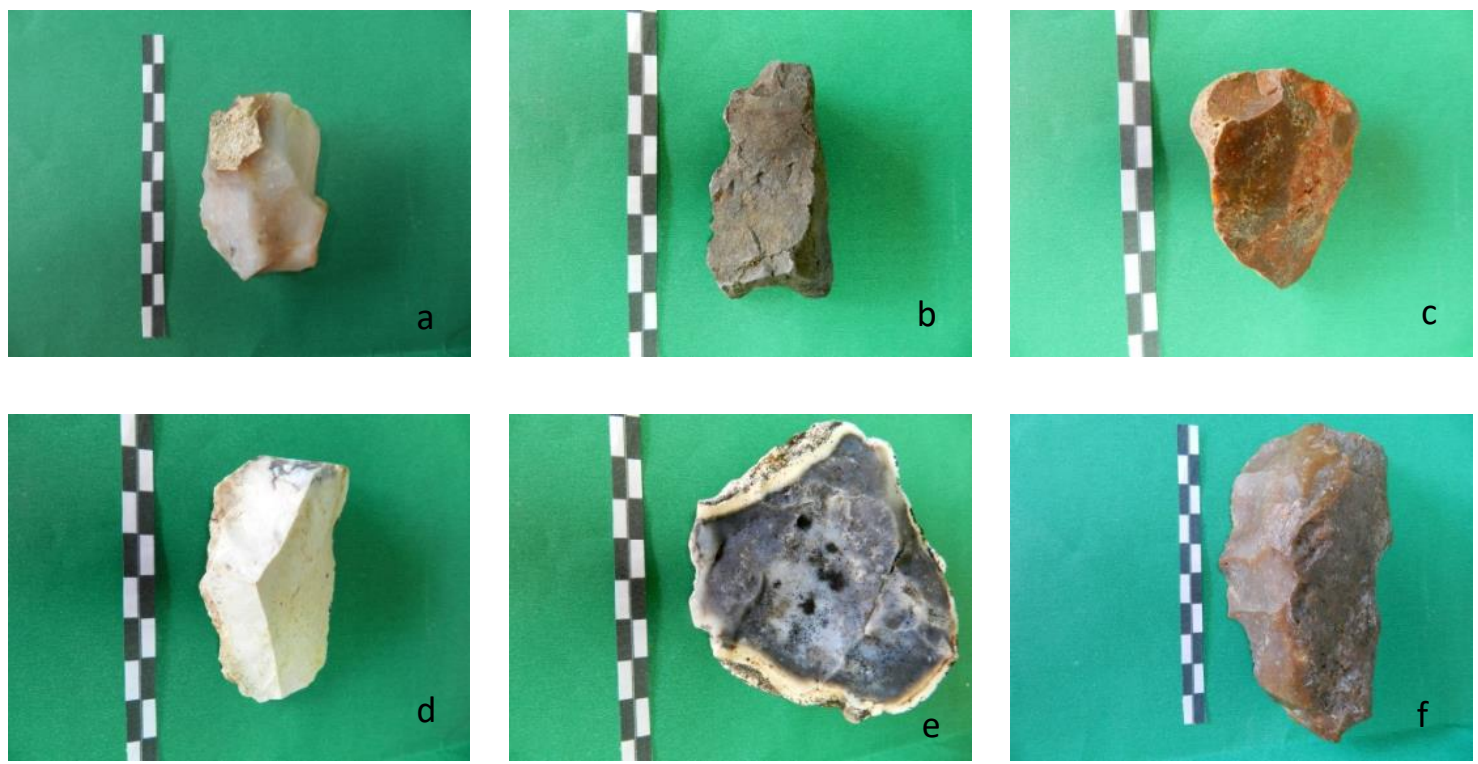

Figura 1: Fragmentos de materiais líticos com tonalidades e graus variados de silicificação - a) fragmento vítreo com predominância de moléculas de calcedônia; b) cor escura; c) cor avermelhada; d) cor branca; e) parte interna escura e recoberta por crosta com sílica; f) fragmento com predominância de moléculas de quartzo criptocristalino. Fonte: Santos Júnior (2013, p.165).

\section{A origem do silexito}

Mas qual seria a gênese dessas rochas silicosas na mesorregião central ou de onde teria vindo todo esse conglomerado de formações rochosas que serviram de matéria-prima para o homem pré-histórico?

A quantidade expressiva de silexito nas áreas dos tabuleiros das microrregiões de Angicos e Santana, assim como a sua presença como fontes de matérias-primas no riacho Pinturas (município de Angicos-RN), com morfologias subangulares, indicavam pouco transporte e com

3 A silicificação é um processo de preservação de estruturas biogênicas que decorre da percolação de águas (fluviais, subterrâneas ou das chuvas) com sais dissolvidos em níveis sedimentares com bioclastos, que leva a permineralização destes, originando novos minerais (através da ocupação dos espaços vazios, mas preservando a estrutura inicial) ou levam à completa substituição do bioclasto por um mineral sem destruir a sua morfologia primária (Medeiros, 2004). 
uma origem em formações geológicas próximas. Duas formações geológicas da Bacia Potiguar podem, teoricamente, explicar a origem desse silexito: a Formação Açu e a Formação Jandaíra.

A Formação Açu se constitui de camadas espessas de arenitos finos a grossos, esbranquiçados, intercalados com folhelhos, argilitos e siltitos, onde foram identificados sedimentos provenientes de leques aluviais e de sistemas fluviais entrelaçados e meandrantes, além de uma transgressão estuarina. As datações com palinomorfos apontam para uma idade do Cretáceo, do período Albiano-Cenomaniano (113 Ma a 93,9 Ma) para esses estratos, mas na parte emersa devem atingir também o Eoturoniano (Cassab, 2003).

Já a Formação Jandaíra na Bacia Potiguar (Figura 2) está composta por uma seção carbonática, sobreposta concordante aos arenitos da Formação Açu e, pelo seu conteúdo fossilífero, é datada do Turoniano (93,9 Ma a 89,8 Ma) ao Eocampaniano (83,6 Ma a 72,1 Ma), sendo composta por calcarenitos e calcilutitos bioclásticos, cujas cores variam do cinza claro ao amarelado, com um nível evaporítico na base.

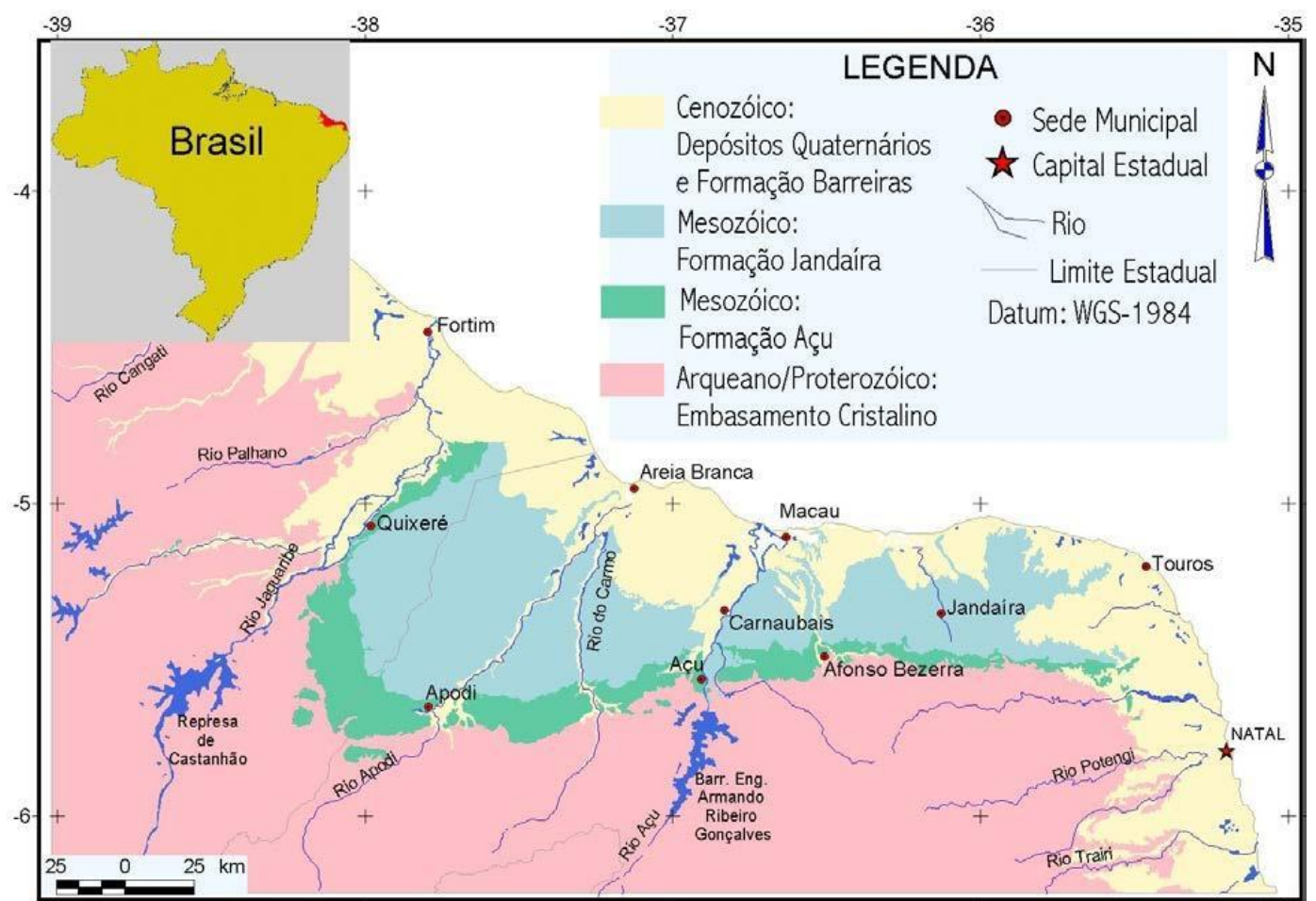

Figura 2: Mapa simplificado da parte emersa da Bacia Potiguar onde pode ser observada a delimitação espacial da Formação Açu e da Formação Jandaíra. Fonte: ANGELIM, 2007. 
A ocorrência de foraminíferos bentônicos, de algas verdes, a presença de marcas de raízes e gretas de contração são características que apontam em sua formação para um ambiente de planície de maré, embora em alguns locais predominasse uma plataforma rasa (Cassab, 2000).

Em alguns pontos da bacia Potiguar ocorre o contato entre essas duas formações, principalmente na entrada do mar da bacia Potiguar marcada pela presença do arenito calcífero (parte superior da Formação Açu) e que representa a transição entre as camadas de folhelhos arenitos da Formação Açu e os sedimentos calcários da Formação Jandaíra.

São observados arenitos cinzentos, argilosos, calcíferos, contendo abundantes fragmentos de conchas de moluscos, que é encontrada na área a leste do rio Açu, decorrentes da megassequência deposicional cronológica marinha, onde se processou o desenvolvimento de extensas plataformas rasas de sedimentação carbonáticas e favoreceram o desenvolvimento de calcários bioclásticos e bioconstruídos que caracterizam as duas formações. Uma fácies dolomítica pode ser observada nos calcários que afloram na parte central da bacia, na área situada entre o rio Açu e um pouco além da margem leste do rio Amargoso (Cassab, 2003).

O pesquisador Narendra Kumar Srivastava, vinculado ao Departamento de Geologia da Universidade Federal do Rio Grande do Norte, também menciona (com. pessoal, 2012) a presença de cinco grandes paleoterraços a leste do rio Piranhas-Açu, contendo paleocascalheiras com diversos nódulos rochosos de diferentes origens mineralógicas, dentre os quais a presença do silexito. Nesses paleoterraços, em diversas áreas de contato do embasamento com os sedimentos cretáceos, o rio Piranhas-Açu depositou espessas cascalheiras que formam três níveis de terraços, encontrando-se atualmente dissecado, mais frequentemente em interflúvios tabulares (Silva, 1999).

Foi observada também a presença dessas paleocascalheiras em três níveis principais a oeste dos rios Açu e Pataxós (tributários do rio Piranhas-Açu), onde foi identificado um aumento progressivo da topografia e da granulometria dos seixos, constatando um padrão escalonado dos terraços do rio Açu, assim como a migração de seus canais, onde a estruturação desses terraços, bem como seus limites, é ordenada por um sistema de falhas normais e fraturas Cenozóicas (Silva, 1999).

A descoberta de dois líticos, em silexito lascados (núcleos), contendo fósseis invertebrados durante o decorrer das pesquisas arqueológicas na área direta e indireta do Enclave Arqueológico Granito Flores (na divisa entre os municípios de Angicos e Afonso Bezerra-RN), 
trouxe informações sobre a possível origem desses nódulos de silexitos para lascamentos utilizada pelos grupos pré-históricos da região.

Como não foi possível encontrar o silexito em camadas, cuja origem ainda não é bem conhecida (SUGUIO, 2003), a análise desses silexitos fossilíferos contendo moldes interno e externo de espécies com conchas e carapaças de animais marinhos, poderia dar indícios da origem desse sedimento carbonático que sofreu substituição química por sílica (Araújo, 1991).

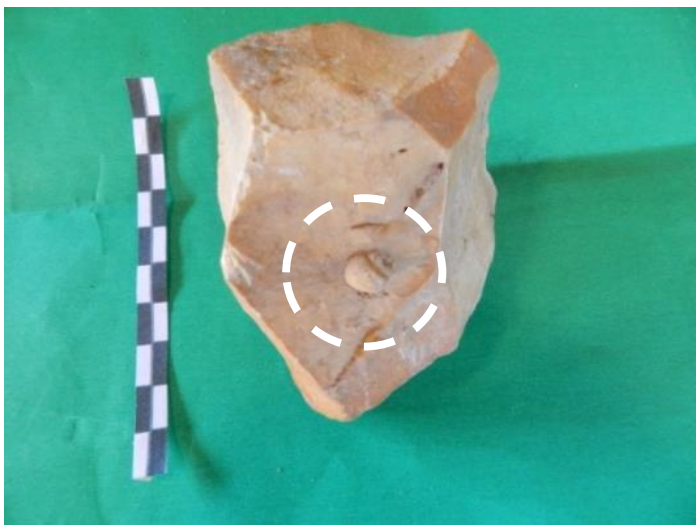

Figura 3: Lítico em silexito contendo molde interno de gastrópode (detalhe no círculo tracejado na cor branca). Fonte: Santos Júnior, 2013.

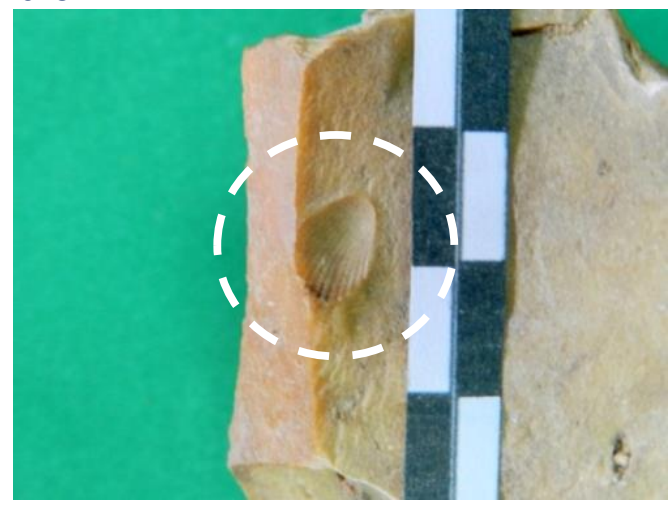

Figura 5: Lítico em silexito contendo molde externo da Classe Bivalvia (detalhe no círculo tracejado na cor branca). Fonte: Santos Júnior, 2013.

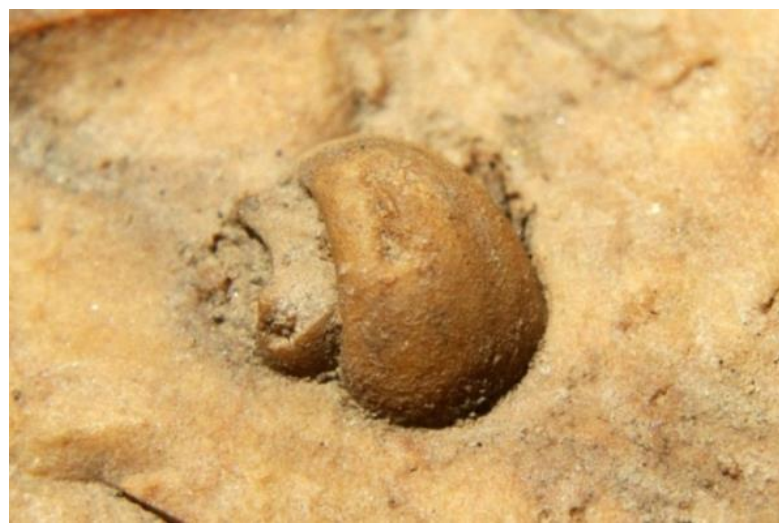

Figura 4: Detalhe ampliado do molde interno de gastrópode do lítico em silexito. Fonte: Santos Júnior, 2013.

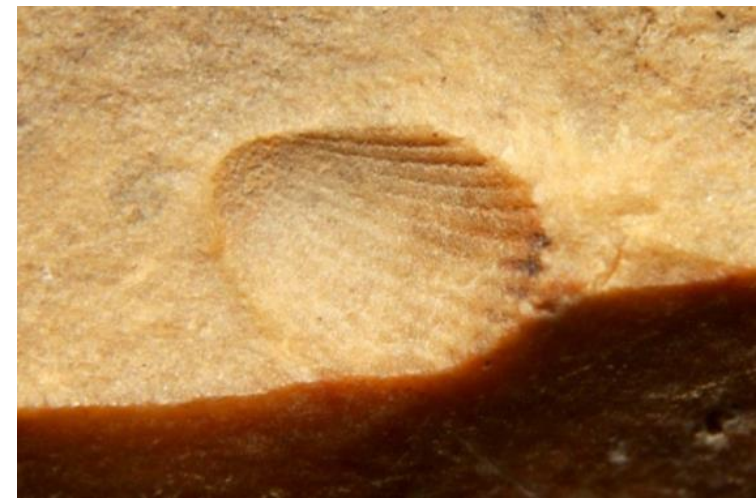

Figura 6: Detalhe ampliado do molde externo da Classe Bivalvia existente no lítico em silexito. Fonte: Santos Júnior, 2013.

O primeiro desses líticos em silexito foi localizado durante uma sondagem arqueológica realizada em um abrigo rochoso intitulado Tupá 02, localizado ás margens do riacho do Tupá, na fazenda Nazaré, município de Fernando Pedrosa-RN. O lítico (núcleo) estava localizado em nível de superfície, na entrada do abrigo e, provavelmente, foi carreado por enchentes do riacho do Tupá e acabou se depositando na entrada do abrigo (o riacho fica situado a apenas 5 metros do abrigo). O lítico apresentava dois elementos fossilíferos: um molde interno (Figuras 
A Utilização das Fontes do Silexito pelos Grupos Pré-Históricos e sua Redistribuição Espacial na Mesorregião Central do Rio Grande do Norte, Brasil.

3 e 4), constituído por uma carapaça de espécie de gastrópode, na parte interna do lítico, ou seja, após o seu lascamento e um molde externo (Figuras 5 e 6), constituído por uma impressão (tipo negativo) de espécie de Bivalvia, também na parte interna do lítico.

Outro exemplar de lítico em silexito também contendo um molde externo de Bivalvia (vide figura 7) foi localizado no leito do riacho Pinturas (coordenadas geográficas em UTM 24 M 0772992 - 9383443 Datum WGS84), em uma das fontes de matérias-primas identificadas na área direta do Enclave Arqueológico Granito Flores, evidenciando a recorrência da existência desses fósseis nos fragmentos de silexito da região.

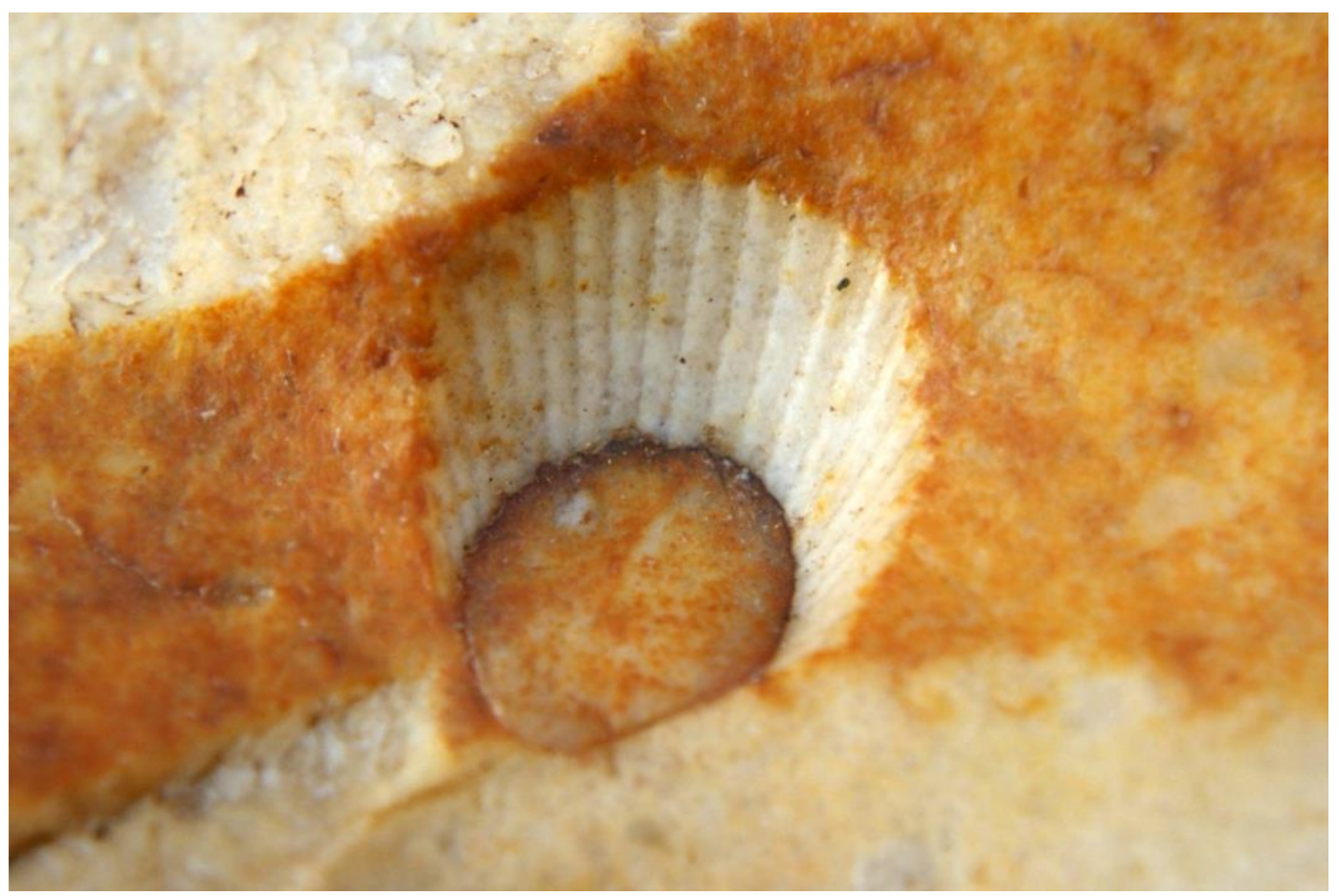

Figura 7: Lítico em silexito localizado no leito do riacho Pinturas (Flores), contendo molde externo da Classe Bivalvia. Fonte: Santos Júnior, 2013.

As associações fossilíferas presentes na Formação Jandaíra tornaram-se conhecidas somente a partir de 1925, com exemplares das coleções organizadas por Roderic Crandall, procedentes de diversas localidades da bacia Potiguar onde, apesar das diferenças na composição das faunas, havia sempre um fóssil característico do Cretáceo e, em 1934, C.J. Maury, após analisar essas coleções, publicou um trabalho onde identificou 17 espécies de bivalves, 12 de gastrópodes e 7 de equinoides, comparando o material estudado com o de outras faunas sincrônicas da Venezuela, Colômbia e México, concluindo que os calcários dessa formação geológica deveriam ser datados no Turoniano (93 Ma a 89,3 Ma). (Maury, 1925). 
A maioria desses fósseis da Classe Bivalvia geralmente está preservada sob a forma de moldes internos (tal como os dois casos aqui apresentados), tornando a identificação das espécies mais difícil. Já a Classe Gastropoda é a que possui maior número de espécies de invertebrados, ocorrendo predominantemente nos ambientes aquáticos (Cassab, 2003). Portanto, se esses fósseis são do ambiente marinho, originários da Formação Jandaíra, o processo de silicificação ${ }^{4}$ deles nas rochas carbonáticas que deram origem a esses exemplares de silexito, só podem ter ocorrido de forma posterior ao período Turoniano (93,9 Ma a 89,3 Ma) ou, pelo menos, de forma concomitante, haja vista que a existência de quase todos os nódulos de sílex parece resultar da substituição de carbonatos, na fase em que a vasa carbonática ainda não tinha sido consolidada (Suguio, 2003).

Se a formação desses nódulos de silexito se processou a partir das vasas carbonáticas da Formação Jandaíra, onde estaria especificamente a origem desses depósitos de silexito na mesorregião central Potiguar? Suguio (2003), alerta que a maioria desses depósitos de silexito tem origem controvertida, que alguns desses depósitos preservam estruturas primárias comuns em carbonatos alóctones, tais como estratificações cruzadas, oólitos, conchas, que seriam indicativos de silexito secundário.

O professor Narendra (2012, com. pessoal) mencionou a hipótese desse material de silexito ser provindo de conhecidos sistemas regionais de falhas geológicas subterrâneas, que permitiram que ocorresse a redistribuição desses nódulos e concreções ao longo dos paleoterraços fluviais e tributários, principalmente a leste da bacia hidrográfica Rio Piranhas-Açu. Duas dessas falhas geológicas passam bem próximas do Enclave Arqueológico Granito Flores: a falha de Afonso Bezerra, com direcionamento NW-SE, tem seu lineamento por cerca de $100 \mathrm{~km}$ e o sistema de falhas de Carnaubais que exerce um forte controle no desenvolvimento do arcabouço tectônico da bacia Potiguar (Matos, 1992).

O sistema de falhas de Afonso Bezerra se constitui em um agrupamento de fraturas com alinhamento na direção NW-SE, desde o sul de Lages-RN até o sudeste de Macau, com 200 km

\footnotetext{
4 A silicificação é também comum em conchas marinhas originárias do carbonato de cálcio. Neste caso duas possibilidades são consideradas, com base no registro fóssil. Na primeira ocorre rápida substituição de calcita por sílica. As águas percolantes estariam subsaturadas em relação ao carbonato de cálcio e supersaturadas para a sílica. Assim, a água funcionaria como um solvente para o carbonato, ao mesmo tempo em que promoveria a precipitação da sílica nos espaços onde o carbonato foi dissolvido. Este mecanismo é determinado pela acidez do meio, criado pela decomposição das proteínas presentes na concha recém-morta, ou por resíduos de matéria orgânica do ambiente. A acidez provoca a dissolução do carbonato de cálcio e a precipitação simultânea da sílica. A estrutura original da concha, em processo de dissolução, estaria separada apenas por uma fina lâmina de água da estrutura silicificada que a substituirá. Este processo pode preservar detalhes da estrutura original da concha (Medeiros, 2004).
} 
A Utilização das Fontes do Silexito pelos Grupos Pré-Históricos e sua Redistribuição Espacial na Mesorregião Central do Rio Grande do Norte, Brasil.

de comprimento e 5 a $20 \mathrm{~km}$ de largura (Figura 8). Esse sistema de falhas exerce influência topográfica sobre várias feições geomorfológicas da região, notadamente na porção centronorte da bacia Potiguar e nos sedimentos clásticos dos paleoterraços, com suas cascalheiras do rio Piranhas-Açu (Hackspacher, 1985).

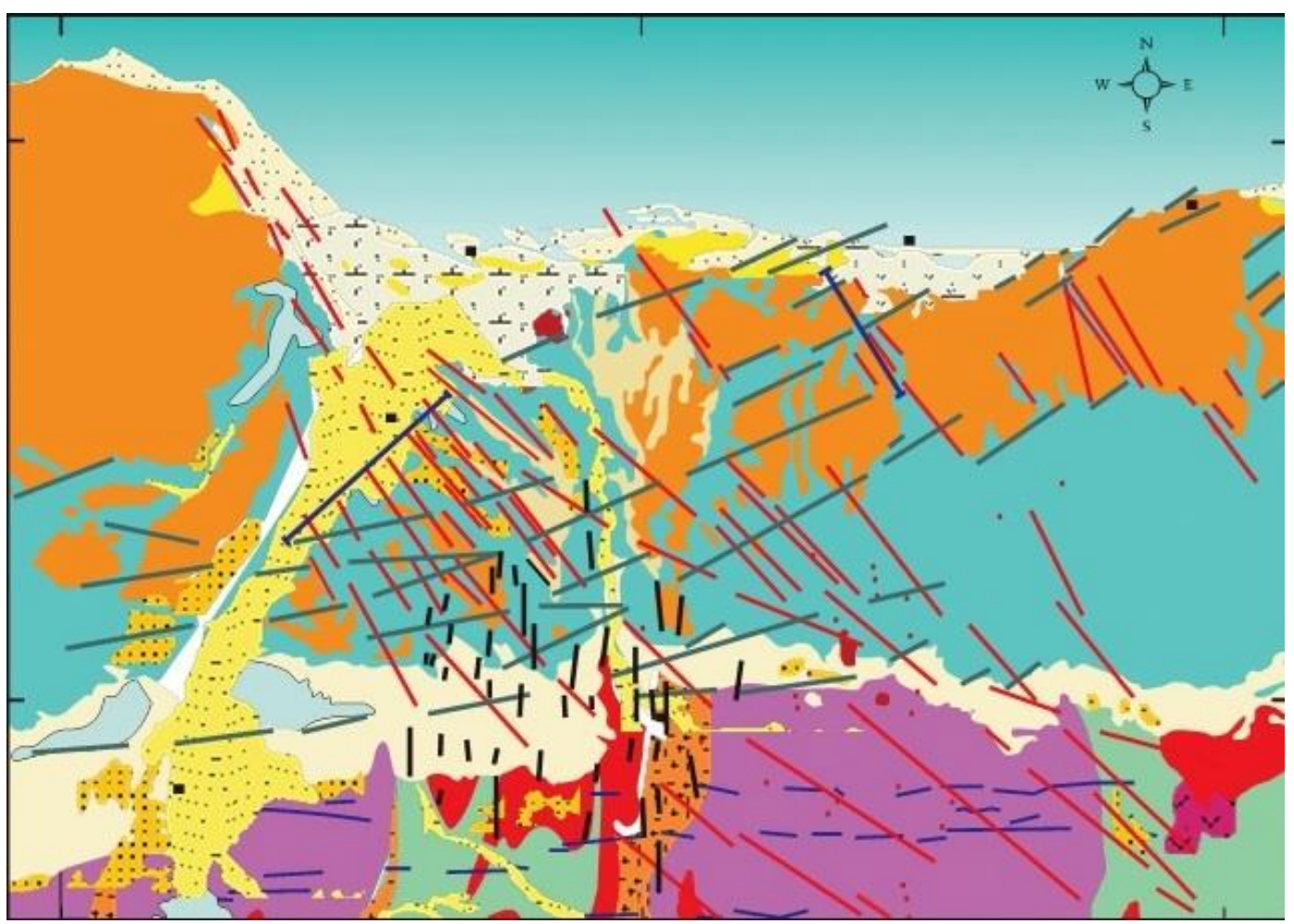

Figura 8: Mapa geológico apresentando a superposição das falhas de Carnaubais (FC) e Afonso Bezerra (FAB) na porção centro-norte da Bacia Potiguar. Fonte: Dantas, 1998 (adaptado pelo autor).

Dessa forma a topografia regional está fortemente relacionada a esse sistema de falhas Afonso Bezerra ${ }^{5}$, onde os vales de drenagens, a leste do rio Piranhas-Açu, escavam os depósitos quaternários e expõe a subjacente Formação Jandaíra ao longo dos vales dos rios.

Várias observações de campo indicam que essas falhas em escala mesoscópica afetaram rochas das formações Açu, Jandaíra, Macau e Barreiras, entretanto tais falhas ocorrem predominantemente em rochas cretáceas das formações Açu e Jandaíra (Moura Lima, 2011).

Consequentemente este material de nódulos de silexito, arenitos e rochas cristalinas estão relacionados à presença dessas falhas geológicas. O silexito preenche as falhas geológicas em vários tipos de rocha, sendo que parte destas falhas é silicificação de rochas da Formação

5 Este sistema de falhas (Afonso Bezerra) ainda se reflete em escala de afloramento, por meio de juntas, falhas comuns ou silicificadas e bandas de deformação, afetando principalmente as formações Açu, Jandaíra e Barreiras. A silicificação verific ada ao longo das falhas pode conferir a essas um caráter selante. (Moura Lima, 2011). 
Jandaíra (calcários) e parte são da silicificação de rochas cristalinas (Hilário Bezerra, 2012, com. pessoal).

Hackspacker et al. (1985) foi um dos primeiros pesquisadores a reconhecer esse tipo de rocha silicificada pelos fluidos associados ao processo termo-tectônico que pode representar um evento tardio do sistema de falhas de Afonso Bezerra. Esses fluidos aquecidos que teriam solubilizado os quartzos presentes nos sedimentos da Formação Açu ou nos calcarenitos da Formação Jandaíra podem ter origem no aquecimento regional associado ao magmatismo Macau, que provocaram a silicificação do calcário e do arenito e provavelmente percolaram através da zona brechada no calcário, mas a verdadeira origem desses fluidos nesse processo de silicificação está sendo estudada por geoquímicos e ainda é incerta (Dantas, 1998; Moura Lima, et.al., 2011).

Ao indagar a pesquisadora Elissandra Moura Lima (UFRN) sobre a gênese de distribuição desses nódulos de silexito, dos arenitos e rochas cristalinas silicificadas e o correspondente processo dessa silicificação ocorrida no interior dessas falhas ela menciona fatores tectônicos na região:

\begin{abstract}
Sim, são provenientes de falhas geológicas. Os esforços tectônicos provocaram o quebramento/fraturamento relativamente profundo dos Arenitos da Formação Açu e calcários da Formação Jandaíra. Os fluidos (líquidos) ricos em sílica advindos das profundezas percorreram essa zona de quebramento, ao longo dos planos de fraturas (as falhas geológicas). Este líquido rico em sílica reagiu química e fisicamente com as rochas, a qual ele estava percolando. Desta forma as rochas foram silicificadas, em diferentes graus, formando inclusive a calcedônia (o silexito) matéria-prima do material arqueológico que tem sido encontrado na região. (Moura Lima, 2012 comunicação via e-mail em 29.12.2012).
\end{abstract}

O material silicificado dos calcários da Formação Jandaíra e arenitos da Formação Açu e da Formação Barreiras decorrentes desse Sistema de Falhas de Afonso Bezerra produziram lineamentos bem identificáveis nos altos topográficos da região, entre os quais os chamados "serrotes" muito comuns na mesorregião Potiguar.

A partir de tais serrotes ${ }^{6}$, uma boa parte desse material contendo nódulos de silexito, assim como outras rochas cristalinas também em graus diferenciados de silicificação, podem ter sido

\footnotetext{
${ }^{6}$ Muitos dos serrotes da região estão preservados porque seus topos são formados por este material silicificado, muito resisten tes à erosão. Mas com o passar do tempo geológico, essas rochas silicificadas sofrem intemperismo, especialmente físico, são desagregadas em forma de blocos de tamanhos diversos e sofrem transporte. Esse transporte pode ser por força da gravidade, rolando os blocos morro à baixo ou pode ser por outros agentes, como a correnteza de rios (Moura Lima, 2011).
} 
A Utilização das Fontes do Silexito pelos Grupos Pré-Históricos e sua Redistribuição Espacial na Mesorregião Central do Rio Grande do Norte, Brasil.

transportados para áreas com altimetria mais baixa transportados, entre outros fatores, pela rede de drenagem local e redistribuídos nos leitos e/ou nas margens dos rios e riachos intermitentes.

Essa hipótese explicaria essa redistribuição caótica de materiais clásticos em forma de nódulos, em diversos espaços altimétricos diferenciados das microrregiões de Angicos e Santana, originando as inúmeras fontes de matérias-primas para os grupos pretéritos que incluem as variações com diversos grupos de rochas silicificadas de silexito.

Um dos exemplos práticos da influência desse processo de silicificação em rochas carbonáticas da Formação Jandaíra provindos do sistema de falhas de Afonso Bezerra e que pode explicar, em parte, a origem dessas fontes de matérias-primas de uso do homem pré-histórico, pode ser vista no entorno da Lagoa do Queimado (localizada a $40 \mathrm{~km}$ da área do Enclave Arqueológico Granito Flores, na direção NW), no município de Pendências-RN, onde podem ser vistas rochas brechadas $^{7}$ e silicificadas, apresentando fragmentos de calcário imersos em uma matriz fina carbonática, com calcedônia e opala.

Naquela área podem ser vistas diversas formações calcárias com vestígios de substituição molecular que indicam esses processos iniciais de silicificação (Figuras 9 e 10).

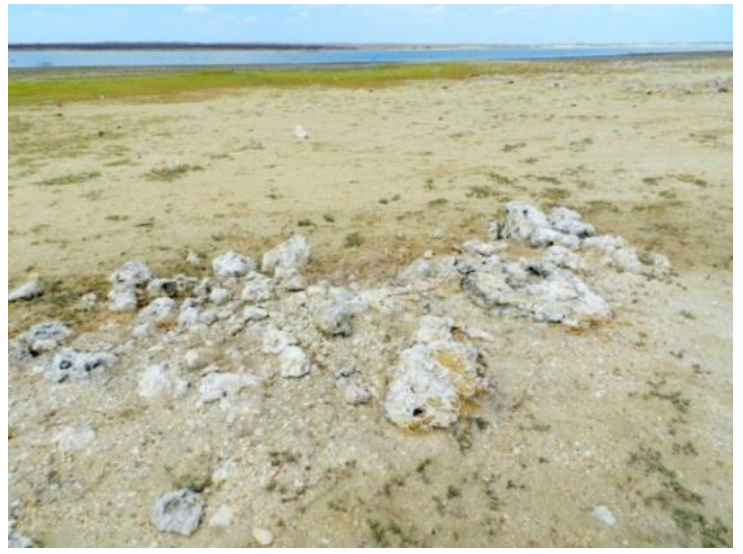

Figura 9: Visão do contexto geoambiental da Lagoa do Queimado Em primeiro plano - rochas calcárias com processos de silicificação (brechas hidráulicas), Pendências-RN. Fonte: Santos Júnior, 2013, p.174.

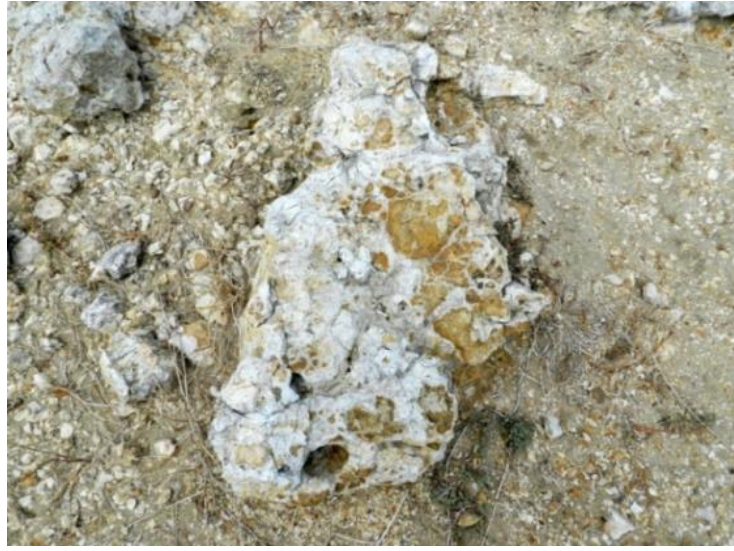

Figura 10: Detalhe de rocha calcária com processo de silicificação que dá origem ao silexito brechóide. Lagoa do Queimado - Pendências - RN. Fonte: Santos Júnior, 2013, p.174.

7 A formação dessas rochas brechadas seria decorrente de processos de silicificação, seguida de uma espécie de explosão decorrente do alívio de pressão sofrido pelos fluidos (com temperaturas próximas do 100을 ) ascendentes provenientes da diminuição de volume da rocha encaixante durante esse processo de silicificação (Moura Lima, 2011). 
A possibilidade de boa parte de rochas silicosas terem se transformado em silexito tem origem a partir dessas falhas geológicas (principalmente o Sistema de Falhas Afonso Bezerra) é bastante plausível, devido à influência aos direcionamentos naturais no sentido NW-SE de drenagem secundária do rio Piranhas-Açu e explicaria, em parte, a presença dessas matériasprimas rochosas na área:

A drenagem secundária associada ao Rio Açu, assim como algumas lagoas próximas, tais como as lagoas do Queimado, da Pedra e Vargem de Cima estão fortemente orientadas segundo a direção NW-SE, sugerindo o controle do SFAB (Sistema de Falhas Afonso Bezerra) sobre estes afluentes. (Dantas, 1998, p.74).

\section{Considerações Finais}

Neste artigo foi levantada uma hipótese de cunho geológico, quanto à origem e diversidade das fontes de matéria-prima de silexito existentes nas paleocascalheiras das microrregiões de Angicos, da Serra de Santana e do Vale do Açu, que abrange a mesorregião Central do Rio Grande do Norte.

A influência de fluidos subterrâneos e de superfície, a partir dos Sistemas de Falhas geológicas regionais de Afonso Bezerra e Carnaubais, parecem ter influído decisivamente nos processos de silicificação das rochas carbonáticas das Formações Jandaíra e Açu, gerando nódulos de rochas silicificadas que constituem o grupo dos silexitos e sua consequente distribuição espacial depositados nos pedimentos detríticos, nas margens dos tributários e paleoterraços fluviais da bacia hidrográfica do rio Piranhas-Açu.

As fontes de matéria-prima existentes, nos lugares arqueológicos a céu aberto e em lugares arqueológicos fechados da mesorregião central, evidenciam a hipótese de um processo natural de redistribuição do silexito para outros espaços regionais do Rio Grande do Norte, vinculados principalmente à área arqueológica do Seridó, do Agreste e dos inúmeros lugares com vestígios líticos de silexito existentes nas dunas que abrangem quase toda a costa litorânea Potiguar.

Portanto, a partir da localização espacial dessas fontes de matérias de silexito, foi possível elaborar um modelo hipotético (em nível macroambiental) de obtenção e transporte pelos grupos pretéritos, do silexito em direção as demais regiões do Rio Grande do Norte, utilizando principalmente as vias hidrográficas do rio Piranhas/Açu, entre elas, o caminho natural do 
riacho Salgadinho, indo na direção SE, até se encontrar com o rio Salgado (ou Amargoso) para, em seguida, ir à direção NE, até desaguar no rio Piranhas/Açu (próximo ao delta estuarino) em um percurso médio de $50 \mathrm{~km}$ ou para o rio Piranhas/Açu na direção $\mathrm{W}$, em um percurso de 43 $\mathrm{km}$.

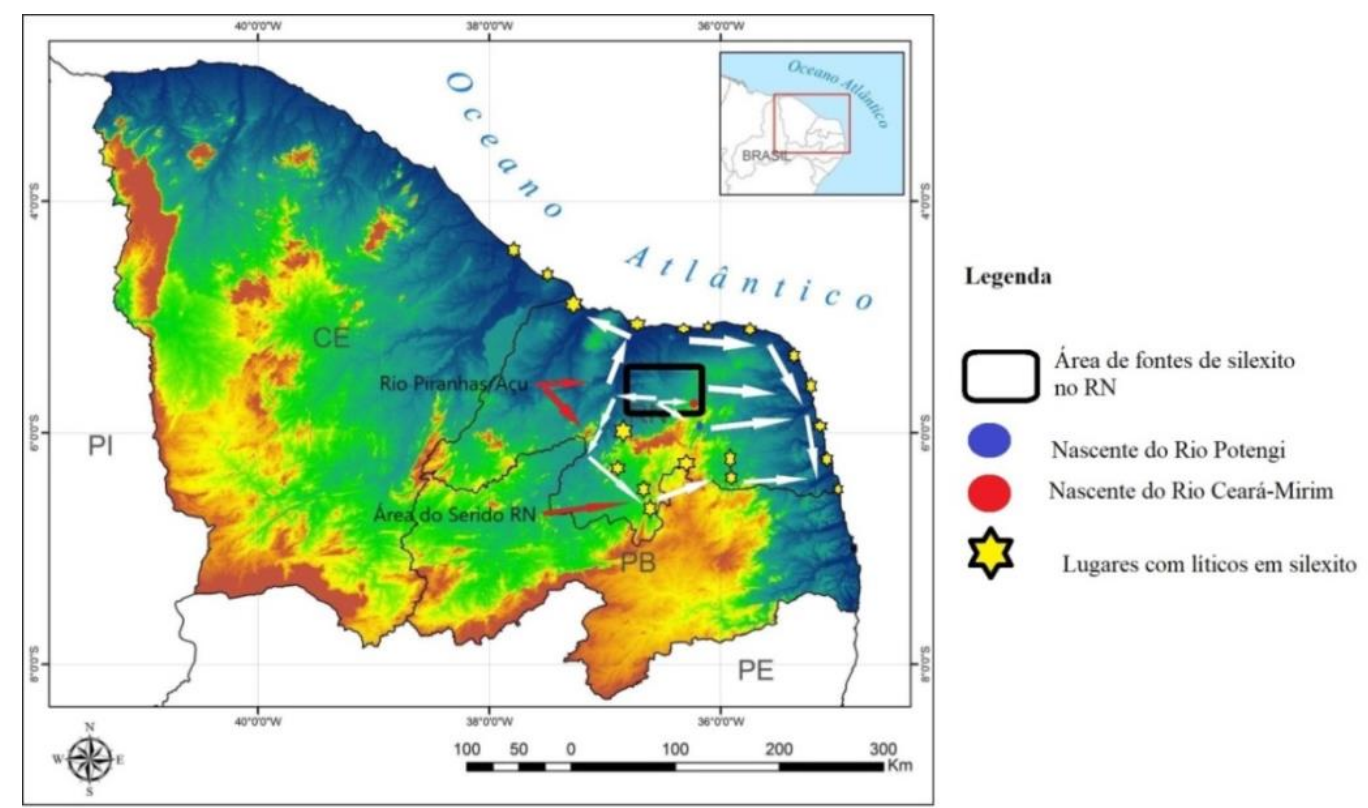

Figura 11: Modelo hipotético de redistribuição do silexito para outras regiões do Rio Grande do Norte. Fonte: Santos Júnior, 2013, p.290.

A partir do delta que constitui a foz do rio Piranhas/Açu, existe uma série de sítios arqueológicos dunares com vestígios de silexito (com núcleos, lascas e instrumentos) em direção ao L para os municípios de Macau, Guamaré, Galinhos, Caiçara, São Bento do Norte, São Miguel do Gostoso, Touros, indo até o litoral Oriental, na divisa com o estado paraibano; e na direção W para os municípios de Porto do Mangue e Areia Branca, chegando até a divisa com o estado cearense (Nascimento; Luna, 1997; Silva, 2003; Albuquerque; Spencer, 1994).

A presença do silexito que aparece nesses sítios dunares litorâneos, pode ser observada através de vestígios líticos em forma de lascas e núcleos, furadores, raspadores simples e raspadores plano-convexo, assim como microlíticos e estilhas com lascamentos por pressão direta e indireta e também a técnica bipolar, com características associadas à Tradição Itaparica, mais seria necessário, principalmente, localizar as jazidas de matérias-primas que foram usadas na fabricação dos utensílios líticos e cerâmicos (Martin, 1999; Albuquerque; Spencer, 1994). 
Já em direção ao Seridó potiguar, os caminhos naturais seriam os tributários que desaguam no rio Piranhas/Açu que segue na direção S onde, por sua vez, recebe as águas do rio Seridó (no município de São Fernando) para, em seguida, ir em direção L (onde se encontra com as águas do rio Acauã) chegando, portanto, a região do Seridó onde também aparecem instrumentos líticos de silexito (Martin, 1999).

Outros caminhos migratórios naturais desse processo seriam dois rios, Ceará-Mirim e Potengi, que tem suas nascentes próximas às microrregiões de Angicos e da Serra de Santana e seguem na direção L, até desaguar no litoral Oriental.

Dessa forma, a utilização das vias fluviais regionais explicaria a presença do silexito, sejam em forma de instrumentos (incluindo as pontas de projéteis da chamada Tradição Potiguar), núcleos, lascas e restos de debitagem, nos lugares arqueológicos identificados em outras áreas do Estado do Rio Grande do Norte.

\section{Referências}

AlBuQUerQue, P. T. de S.; SPENCER, W.B. 1994. Projeto arqueológico: O Homem das Dunas. Revista Clio Arqueológica, no 10, v. 1, UFPE, Recife-PE. pp. 175 a 188.

ANGELIM, L. A. A. et. al. 2007. Geologia e recursos minerais do Estado do Rio Grande do Norte - Escala 1:500.000. Recife: CPRM - Serviço Geológico do Brasil, $119 \mathrm{p}$.

ARAÚJO, A. G. de M. 1991. As rochas silicosas como matéria-prima para o homem pré-histórico: variedades, definições e conceitos. Revista do Museu de Arqueologia e Etnologia, v. 1, São Paulo, pp. 105-11.

CALÇA, C.P. 2008. Microbiota fóssil de sílex da Formação Assistência (subgrupo Irati, Permiano, Bacia do Paraná) no Estado de São Paulo. Dissertação (Mestrado em Arqueologia) - Instituto de Geociências, Programa de Pós-Graduação em Geologia Sedimentar, Universidade de São Paulo (USP), 93 p.

CASSAB, R. de C. T. 2003. Paleontologia da Formação Jandaíra, Cretáceo Superior da Bacia Potiguar, com ênfase na paleobiologia dos gastrópodos. Tese (Doutorado em Geologia). Programa de Pós-Graduação em Geologia. Instituto de Geociências - UFRJ, D. Sc. 184 p.

DANTAS, E. P. 1998. Gravimetria e sensoriamento remoto: uma aplicação ao estudo da tectônica recente entre Macau e São Bento do Norte (RN). Dissertação (Mestrado em Geofísica) - Programa de PósGraduação em Geodinâmica e Geofísica. Centro de Ciências Exatas e da Terra, Universidade Federal do Rio Grande do Norte. 122 p.

HACKSPACKER, P. C. et al. 1985. Falha de Afonso Bezerra como evidência de significativo tectonismo frágil NW -SE, na Bacia Potiguar emersa (RN) Natal: Universidade Federal do Rio Grande do Norte/Centro de Ciências Exatas e da Terra/Departamento de Geologia. Boletim, v. 10, p. 33-44.

MARTIN; G. 1999. Pré-história do Nordeste do Brasil. 3a ed. Recife: UFPE. 
MAURY, C. J. 1925. Fósseis terciários do Brasil com descrição de novas formas cretáceas. Monografia do Serviço Geológico e Mineralógico do Brasil, 4.665 p.

MATOS, R. M. D. 1992. The northeast brazilian rift system. Tectonics. 11(4):766-791.

MEDEIROS, J. da S. 2004. Análise dos fatores responsáveis pela alta salinidade do aquífero fissural da microbacia do Riacho do Feijão - Pedro Avelino-RN. Dissertação (Mestrado em Geociências) - Centro de Ciências Exatas e da Terra, Programa de Pesquisa e Pós-Graduação em Geociências, UFRN, 80 p.

MENESES, S. de O. 2008. Estudo das rochas por exame macroscópico. Dissertação (Mestrado em Geociências) - Programa de Geociências da Universidade Federal de Juiz de Fora. 78 p.

MOURA-LIMA, E. N. et al. 2011. Reativação cenozoica do sistema de falhas de Afonso Bezerra, bacia potiguar. Geociênc. (São Paulo), São Paulo, v. 30, n. 1, pp. 77-93.

NASCIMENTO, A.; LUNA, S. 1997. A cerâmica arqueológica dos sítios dunares no Rio Grande do Norte Brasil. Revista Clio Arqueológica - UFPE, volume 01, № 12, pp. 17-25.

SILVA, M. G. da. 1999. Caracterização de minerais pesados ao longo do Rio Piranhas-Açu: distribuição e proveniência. Dissertação (Mestrado em Geologia) - Universidade Federal do Rio Grande do Norte, Programa de Pós-Graduação em Geodinâmica e Geofísica, UFRN, , 67 p.

SILVA, M. L. da 2003. Caracterização dos sítios arqueológicos em dunas do litoral oriental do Rio Grande do Norte, Brasil. Dissertação (Mestrado em História/concentração em Pré-História) - Programa de Pósgraduação em História, Universidade Federal de Pernambuco, Recife, 96 p.

SUGUIO, K. 2003. Geologia sedimentar. São Paulo: Edgard Blucher Ltda, 400p. 